\title{
Paper
}

Title

\section{Thermal Transformation and Ionic Conductivity of Ammonium Ion-Exchanger Prepared from Na-4-mica}

Author's Name

\author{
Seiichi TARUTA*, Takashi KAGA, \\ Tomohiro YAMAGUCHI and Kunio KITAJIMA
}

Author's Affiliation

Department of Chemistry and Materials Engineering, Faculty of Engineering, Shinshu University,

4-17-1 Wakasato, Nagano-shi, Nagano 380-8553, Japan

*Corresponding Author

Seiichi TARUTA

Department of Chemistry and Materials Engineering, Faculty of Engineering, Shinshu University,

4-17-1 Wakasato, Nagano-shi, Nagano 380-8553, Japan

TEL: +81-26-269-5416

FAX: +81-26-5424 


\title{
E-mail: staruta@shinshu-u.ac.jp
}

\begin{abstract}
Ammonium ion exchange of Na-4-mica and thermal transformation of the ion-exchanger were investigated and the conductivities of the heated ion-exchangers were estimated. More than $95.4 \%$ of $\mathrm{Na}^{+}$ions in the interlayer of the $\mathrm{Na}-4$-mica could be substituted by $\mathrm{NH}_{4}{ }^{+}$ions after repeating ion exchange four times. Almost of $\mathrm{NH}_{4}{ }^{+}$ ions remained in the interlayer at $700{ }^{\circ} \mathrm{C}$ and they were completely decomposed into protons at $900{ }^{\circ} \mathrm{C}$. The conductivities of the ion-exchangers heated at $700-900{ }^{\circ} \mathrm{C}$ were $10^{-7}-10^{-6} \mathrm{~S} / \mathrm{cm}$ at $700{ }^{\circ} \mathrm{C}$. The conduction mechanism of the ion-exchangers heated at $700{ }^{\circ} \mathrm{C}$ and $800{ }^{\circ} \mathrm{C}$ was $\mathrm{NH}_{4}{ }^{+}$ion migration in the interlayer and that of the ion-exchanger heated at $900{ }^{\circ} \mathrm{C}$ was proton migration. However, the contribution of residual $\mathrm{Na}^{+}$ions to the conduction can not be excluded.
\end{abstract}

Keywords; Mica, Ion exchange, Ammonium ion, Ionic conductivity 


\section{Introduction}

Na-4-mica is a highly charged sodium fluorophlogopite mica $\left(\mathrm{Na}_{4} \mathrm{Mg}_{6} \mathrm{Al}_{4} \mathrm{Si}_{4} \mathrm{O}_{20} \mathrm{~F}_{4}\right)$ of which interlayer contains twice as many $\mathrm{Na}^{+}$ions as that of the ordinary Na-type fluorophlogopite $\left(\mathrm{Na}_{2} \mathrm{Mg}_{6} \mathrm{Al}_{2} \mathrm{Si}_{6} \mathrm{O}_{20} \mathrm{~F}_{4}\right)$ contains. It has theoretically high ion-exchange capacity and its cation exchange properties have been investigated [1-10].

We synthesized Na-4-mica by novel and simple solid-state reaction and found that the electrical conductivity of Na-4-mica polycrystal $\left(4.3 \times 10^{-4} \mathrm{~S} / \mathrm{cm}\right.$ at $\left.650{ }^{\circ} \mathrm{C}\right)$ was much higher than that of the ordinary Na-type fluorophlogopite $\left(1.2 \times 10^{-6} \mathrm{~S} / \mathrm{cm}\right.$ at 650 $\left.{ }^{\circ} \mathrm{C}\right)$ [11]. The conductivity mechanism was the movement of $\mathrm{Na}^{+}$ions in the interlayer, which is the same with that of $\beta$-alumina which is well known as $\mathrm{Na}^{+}$ion conductor. On the other hand, K-type fluorophlogopite $\left(\mathrm{KMg}_{3} \mathrm{AlSi}_{3} \mathrm{O}_{10} \mathrm{~F}_{2}\right)$ is the representative synthetic mica, and its electrical resistance is very high. The reasons may be that the size of $\mathrm{K}^{+}$ion in the interlayer is large and the interlayer does not contain as many cations as that of Na-4-mica contains. So if micas have cations with smaller size in the interlayer and/or have many cations in the interlayer like Na-4-mica, they will have a possibility as ionic conductors.

$\mathrm{Na}^{+}$ions in the interlayer of Na-4-mica can be exchanged for other kinds of cations [1-10]. So we thought that it would be easy to fabricate proton, lithium ion or other cations conducting micas by the ion exchange of Na-4-mica. In this study, Ammonium ion exchange of Na-4-mica and thermal transformation of the ion-exchanger were investigated. And because the obtained Ammonium ion-exchanger would be thermally decomposed into proton mica of which the interlayer cation is proton, the conductivities of the heated ion-exchangers were estimated.

\section{Experimental procedure}


Na-4-mica synthesized by the solid phase reaction method [11] was stirred for $1 \mathrm{~h}$ in distilled water, in order to swell the interlayer. And then it was mixed with $1.0 \mathrm{~mol} / \mathrm{l}$ $\mathrm{NH}_{4} \mathrm{Cl}$ solution and stirred for $1 \mathrm{~h}$ at $100{ }^{\circ} \mathrm{C}$. In this way, the interlayer cations, $\mathrm{Na}^{+}$ions, of the Na-4-mica were exchanged for $\mathrm{NH}_{4}{ }^{+}$ions. The ion-exchanger was separated from the solution using a centrifuge. The ion exchange and separation were repeated two to six times. The separated ion-exchangers were washed with distilled water and dried at $60{ }^{\circ} \mathrm{C}$ for $24 \mathrm{~h}$. The phase change, basal spacing (c.sin $\beta$; c and $\beta$ are lattice constants) and lattice constant $\mathrm{b}$ of the ion-exchangers were estimated using an X-ray diffraction (XRD) analyzer (XRD-6000, Shimadzu, Japan). Sodium content of the ion-exchanger was analyzed in the solid state using an atomic absorption spectrophotometer (ContrAA700, Analytik Jena Japan, Japan).

The ion-exchanger prepared by repeating ion exchange four times was compacted by isostatic pressing at $100 \mathrm{MPa}$, dried at $150{ }^{\circ} \mathrm{C}$ for $24 \mathrm{~h}$ and then fired in a sealed platinum container at $200-1000{ }^{\circ} \mathrm{C}$ for $1 \mathrm{~h}$. The characters of the heated ion-exchangers were estimated using the XRD analyzer, a thermogravimetric and differential thermal analyzer (TG, DTA: TG8120, Rigaku, Japan), and a fuorier transmission infrared (FT-IR) spectrometer (FT/IR-4200, JASCO, Japan). Specific electrical resistance of the heated ion-exchangers was measured at $500-700{ }^{\circ} \mathrm{C}$ by a four-probe method using an impedance analyzer (CHEMICAL IMPEDANCE METER 3532-80, HIOKI, Japan) in a frequency range of 4 to $10^{6} \mathrm{~Hz}$. The samples for electrical measurement were prepared as the size of $3 \times 4 \times 25 \mathrm{~mm}$ and were sputtered platinum as electrodes. The distance between the electrodes was about $5 \mathrm{~mm}$. The electrodes and the conducting wires made of platinum were contacted and the contacts were held with the silver paste. The samples and conducting wires were shielded from noises by aluminum foil.

\section{Results and discussion}




\section{1. $\mathrm{NH}_{4}^{+}$ion exchange of $\mathrm{Na}-4-\mathrm{mica}$}

The XRD patterns of the synthesized Na-4-mica and its ion-exchangers are shown in Fig. 1. In the XRD pattern of the synthesized Na-4-mica, dehydrated Na-4-mica and a small amount of unknown materials were observed. The (001) and (003) diffraction peaks of the ion-exchangers appeared at lower diffraction angles, compared with those of the dehydrated Na-4-mica, which indicate that $\mathrm{Na}^{+}$ions in the interlayer of the Na-4-mica were substituted by larger $\mathrm{NH}_{4}{ }^{+}$ions. While the (060) diffraction peak observed at about $60.5^{\circ}$ was not shifted by the ion exchange, new diffraction peak appeared at $59.5^{\circ}$. The new peak might resulted from the diffraction of (33i) lattice plane. The (060) and (33i) diffraction peaks of the Na-4-mica might appeared at $60.5^{\circ}$, like those of fluorophlogopite $\left(\mathrm{KMg}_{3} \mathrm{Si}_{3} \mathrm{AlO}_{10} \mathrm{~F}_{2}\right)$ [12]. By the ion exchange, the interplanar spacing of (060) lattice plane was not varied, but that of (33i) lattice plane was widened.

The $c \cdot \sin \beta$ and $b$ were determined from the (003) and (060) diffraction peaks of the $\mathrm{Na}-4$-mica and the ion-exchangers. The $\mathrm{c} \cdot \sin \beta$ and $\mathrm{b}$ of the Na-4-mica were respectively $9.81 \AA$ and $9.23 \AA$. The $c \cdot \sin \beta$ was increased by repeating ion exchange and became constant value of about $10.0 \AA$ by repeating ion exchange three or more times, while the $b$ value was not almost changed and was constant value of about $9.24 \AA$. These results mean that the substitution of $\mathrm{NH}_{4}{ }^{+}$ions for $\mathrm{Na}^{+}$ions in the interlayer widened only the interlayer but did not influence the $\mathrm{b}$ and the $\mathrm{NH}_{4}{ }^{+}$ion content in the interlayer was almost saturated by repeating ion exchange more than three times.

Sodium content in the ion-exchanger prepared by repeating ion exchange four times was analyzed. It was found that $4.6 \%$ of Na element in the synthesized Na-4-mica remained after the ion exchange. The synthesized Na-4-mica contained traces of sodium fluoride and the unknown materials like sodium compounds. This means that more than $95.4 \%$ of $\mathrm{Na}^{+}$ions in the interlayer of the $\mathrm{Na}-4$-mica were exchanged for $\mathrm{NH}_{4}{ }^{+}$ions. 


\subsection{Change in characters of $\mathrm{NH}_{4}{ }^{+}$ion-exchanger by heating}

The DTA and TG curves of the ion-exchanger prepared by repeating ion exchange four times are shown in Fig. 2. The first weight loss at $150-250{ }^{\circ} \mathrm{C}$ and the endothermic peak at $250{ }^{\circ} \mathrm{C}$ were caused by the evaporation of water in the interlayer. The weight was not varied at $250-500{ }^{\circ} \mathrm{C}$ and was lost gradually at $500-880{ }^{\circ} \mathrm{C}$. The broad endothermic peak was also observed at $350-880{ }^{\circ} \mathrm{C}$. The second weight loss resulted from the decomposition of $\mathrm{NH}_{4}{ }^{+}$ions. The third weight loss at $880-930{ }^{\circ} \mathrm{C}$ and the exothermic peak at $920^{\circ} \mathrm{C}$ were caused by the decomposition of the Na-4-mica type structure and the forth weight loss and the exothermic peak at around $1000{ }^{\circ} \mathrm{C}$ were also caused by the decomposition of the mica structure. These weight losses resulted from the evaporation of fluorine in the ion-exchanger as fluorides with the decomposition.

The FT-IR spectra of the synthesized Na-4-mica, the ion-exchanger prepared by repeating ion exchange four times and the heated ion-exchangers are shown in Fig. 3. For the non-heated ion-exchanger and the ion-exchangers heated at $\leqq 800{ }^{\circ} \mathrm{C}$, characteristic absorption peaks of $\mathrm{NH}_{4}^{+}$were observed at $3200-3300 \mathrm{~cm}^{-1}$ and $1400-1450 \mathrm{~cm}^{-1}$. It was reported that the absorption peak at $3200-3300 \mathrm{~cm}^{-1}$ was observed for $\mathrm{NH}_{4}{ }^{+} \beta$-alumina [13] and $\left(\mathrm{NH}_{4}{ }^{+}-\mathrm{H}_{3} \mathrm{O}^{+}\right) \beta^{\prime \prime}$-alumina [14], and the absorption peak at 1400-1450 $\mathrm{cm}^{-1}$ was observed for $\mathrm{NH}_{4}{ }^{+}$ion-exchanged montmorillonite [15]. These results mean that most of $\mathrm{NH}_{4}{ }^{+}$ions remained in interlayer even at $700{ }^{\circ} \mathrm{C}$ though the $\mathrm{NH}_{4}{ }^{+}$ions in the interlayer began to be decomposed at $350{ }^{\circ} \mathrm{C}$ as show in Fig. 2 . However, a lot of $\mathrm{NH}_{4}{ }^{+}$ions were decomposed at $800{ }^{\circ} \mathrm{C}$ and protons might remain in the interlayer, and $\mathrm{NH}_{4}{ }^{+}$ions disappeared at $900{ }^{\circ} \mathrm{C}$. Almost of the absorption peaks at $400-1100 \mathrm{~cm}^{-1}$ resulted from tetrahedral sheet of mica [16] and the spectra were varied by the heating, which indicate that the ion-exchanger and the heated ion-exchangers 
maintained mica structure but the mica structure was modified gradually by heating.

The XRD patterns of the ion-exchanger and the heated ion-exchangers are shown in Fig. 4. The XRD patterns of the ion-exchangers heated at $200-700^{\circ} \mathrm{C}$ were almost the same with the XRD pattern of the ion-exchanger, which also indicate that $\mathrm{NH}_{4}{ }^{+}$ions remained in the interlayer even at $700{ }^{\circ} \mathrm{C}$. At $800^{\circ} \mathrm{C}$, new diffraction peaks which resulted from (001) and (003) lattice planes of other mica structure were observed at 9.5 ${ }^{\circ}$ and $28.5^{\circ}$. At above $900{ }^{\circ} \mathrm{C}$, the new peaks became stronger and the original mica peaks observed at $9.0^{\circ}$ and $27.0^{\circ}$ disappeared.

The $c \cdot \sin \beta$ and $b$ of the heated ion-exchangers are shown in Fig. 5. The $c \cdot \sin \beta$ and b did not almost vary at $\leqq 400{ }^{\circ} \mathrm{C}$, which indicates that the ion-exchanger retained the structure at $\leqq 400^{\circ} \mathrm{C}$. The $\mathrm{c} \cdot \sin \beta$ became larger than that of the ion-exchanger at 500-700 ${ }^{\circ} \mathrm{C}$ and the $\mathrm{b}$ was decreased gradually with an increase in the heating temperature. These changes were caused by modifying the structure of the ion-exchanger. However, the detail was not unclear. Two values of $c \cdot \sin \beta$ were determined for the ion-exchanger heated at $800{ }^{\circ} \mathrm{C}$. Larger $\mathrm{c} \cdot \sin \beta$ originated in the ion-exchanger which retained $\mathrm{NH}_{4}{ }^{+}$ions in the interlayer and smaller $\mathrm{c} \cdot \sin \beta$ originated in mica of which $\mathrm{NH}_{4}{ }^{+}$ions were decomposed into protons. The $\mathrm{c} \cdot \sin \beta$ became the smallest value at $900{ }^{\circ} \mathrm{C}$, and the $\mathrm{b}$ agreed with that of fluorophlogopite $(9.18 \AA)$. That is, the mica structure was transformed from highly charged Na-4-mica type into normal fluorophlogopite type.

The bulk and true densities of the ion-exchangers heated at 700,800 and $900{ }^{\circ} \mathrm{C}$ were measured and the relative densities were determined from the bulk and true densities. As the results, the relative densities of the ion-exchangers heated at 700, 800 and $900{ }^{\circ} \mathrm{C}$ were respectively $53.4,53.1$ and $58.6 \%$.

\subsection{Ionic conductivities of $\mathrm{NH}_{4}^{+}$ion-exchanger during heating}


The conductivities of the ion-exchangers heated at 700,800 and $900{ }^{\circ} \mathrm{C}$ were respectively, $5.5 \times 10^{-7}, 2.2 \times 10^{-7}$ and $1.7 \times 10^{-7} \mathrm{~S} / \mathrm{cm}$ at $700{ }^{\circ} \mathrm{C}$, which were much lower than the conductivity of the Na-4-mica $\left(6.3 \times 10^{-3} \mathrm{~S} / \mathrm{cm}\right.$ at $\left.700{ }^{\circ} \mathrm{C}\right)$. Before and after the conductivity measurement, there were no changes in the XRD pattern, $c \cdot \sin \beta$ and b of the heated ion-exchangers. That is, $\mathrm{NH}_{4}{ }^{+}$ions in the ion-exchangers were not almost decomposed during the measuring.

The plots of $\log (\sigma \mathrm{T})$ against $1 / \mathrm{T}$ for the ion-exchangers heated at 700, 800 and 900 ${ }^{\circ} \mathrm{C}$ are shown in Fig. 6 ( $\sigma$ : conductivity, T: temperature). They were linear over the temperature range. Then, in accordance with the Arrhenius equation, the activation energies were determined. The activation energy of the ion-exchanger heated at $700{ }^{\circ} \mathrm{C}$ $(1.43 \mathrm{eV})$ were almost the same with that of the ion-exchanger heated at $800{ }^{\circ} \mathrm{C}(1.48$ $\mathrm{eV})$ but was higher than that of the ion-exchanger heated at $900{ }^{\circ} \mathrm{C}(0.70 \mathrm{eV})$. These results indicate that the conduction mechanism of the ion-exchanger heated at $700{ }^{\circ} \mathrm{C}$ was the same with that of the ion-exchanger heated at $800{ }^{\circ} \mathrm{C}$ and might be $\mathrm{NH}_{4}{ }^{+}$ion migration in the interlayer, while that of the ion-exchanger heated at $900{ }^{\circ} \mathrm{C}$ was proton migration. Omi et al. reported that the activation energy for the translational diffusion of acidic proton in $\left(\mathrm{NH}_{4}\right)_{3} \mathrm{H}\left(\mathrm{SO}_{4}\right)_{2}$ was smaller than that for the translational diffusion of $\mathrm{NH}_{4}{ }^{+}$ion [17]. This report supports our consideration. The ion-exchanger heated at 800 ${ }^{\circ} \mathrm{C}$ consisted of not only Na-4-mica type mica of which the interlayer cations were $\mathrm{NH}_{4}{ }^{+}$ ions but also normal fluorophlogopite type mica of which the interlayer cations were protons. The conduction might be controlled by the $\mathrm{NH}_{4}{ }^{+}$ions and the protons did not contribute to the conductivity. In this study, the measured resistance (conduction) of the ion-exchanger polycrystals should consist of the bulk resistance of mica crystals and the grain boundary resistance between mica crystals. The conduction path of $\mathrm{NH}_{4}{ }^{+}$ions was the interlayer, while that of proton might be over the mica crystals. So the conduction of $\mathrm{NH}_{4}{ }^{+}$ions at the grain boundary might occur at interfaces where each interlayer of mica 
crystals was contacted.

The structure of the ion-exchanger became the normal fluorophlogopite type at 900 ${ }^{\circ} \mathrm{C}$. The carrier content in the interlayer became lower than that in the interlayer of the $\mathrm{Na}-4-m i c a$ type. Moreover, $\mathrm{Na}^{+}$ions which remained as sodium fluoride and the unknown materials like sodium compounds might come into the interlayer of the formed fluorophlogopite type mica when the transformation occurred. Therefore, the contribution of the $\mathrm{Na}^{+}$ions to the conduction of the ion-exchanger heated at $900{ }^{\circ} \mathrm{C}$ can not be excluded.

\section{Conclusions}

More than $95.4 \%$ of $\mathrm{Na}^{+}$ions in the interlayer of the synthesized $\mathrm{Na}-4$-mica could be substituted by $\mathrm{NH}_{4}{ }^{+}$ions after repeating ion exchange four times. The decomposition of $\mathrm{NH}_{4}{ }^{+}$ions in the interlayer started at around $350{ }^{\circ} \mathrm{C}$. Almost of $\mathrm{NH}_{4}{ }^{+}$ions remained in the interlayer even at $700{ }^{\circ} \mathrm{C}$ but a lot of $\mathrm{NH}_{4}{ }^{+}$ions was decomposed into proton at 800 ${ }^{\circ} \mathrm{C}$ and $\mathrm{NH}_{4}{ }^{+}$ions disappeared at $900{ }^{\circ} \mathrm{C}$. When the $\mathrm{NH}_{4}{ }^{+}$ions were decomposed, the structure of the ion-exchanger was modified from a highly charged $\mathrm{Na}-4$-mica type into a normal fluorophlogopite type. The conductivities of the ion-exchanger heated at 700 , 800 and $900{ }^{\circ} \mathrm{C}$ were $10^{-7}-10^{-6} \mathrm{~S} / \mathrm{cm}$ at $700^{\circ} \mathrm{C}$. The conduction mechanism of the ion-exchangers heated at $700{ }^{\circ} \mathrm{C}$ and $800{ }^{\circ} \mathrm{C}$ was $\mathrm{NH}_{4}{ }^{+}$ion migration in the interlayer. That of the ion-exchanger heated at $900{ }^{\circ} \mathrm{C}$ was proton migration. However, the contribution of residual $\mathrm{Na}^{+}$ions to the conduction can not be excluded. 


\section{Acknowledgement}

This research was supported by The Iwatani Naoji Foundation's Research Grant and a Grant-in-Aid for Scientific Research from the Ministry of Education, Science, Sports and Culture, Japan. 


\section{References}

[1] S. Komarneni, R. Pidugu, J. E. Amonette, J. Mater. Chem. 8 (1998) 205-208.

[2] T. Kodama, S. Komarneni, J. Mater. Chem., 9 (1999) 2475-2480.

[3] S. Komarneni, R. Pidugu, W. Hoffbauer, H. Schneider, Crays Clay Miner. 47 (1999) 410-416.

[4] T. Kodama, S. Komarneni, W. Hoffbaue, H. Schneider, J. Mater. Chem. 10 (2000) 1649-1653.

[5] T. Kodama, M. Ueda, Y. Nakamuro, K. Shimizu and S. Komarneni, Langmuir 20 (2004) 4920-4925.

[6] W. J. Paulus, S. Komarneni, R. Roy, Nature 357 (1992) 571-573.

[7] K. R. Franklin, E. Lee, J. Mater. Chem. 6 (1996) 109-115.

[8] M. Park, D. H. Lee, C. L. Choi, S. S. Kim, K. S. Kim, J. Choi, Chem. Mater. 14 (2002) 2582-2589.

[9] T. Kodama, S. Komarneni, J. Mater. Chem. 9 (1999) 533-539.

[10] S. Komarneni, W. J. Paulus, R. Roy, in: Proc. International Conference Ion Exchange (ICIE ‘91), Tokyo, 1991, Kodansha, Tokyo (1991) pp.51-56.

[11] S. Taruta, S. Shimodaira, T. Yamaguchi, K. Kitajima, Mater. Lett. 60 (2006) 464-466.

[12] Card No. 16-344, Joint Committee on Powder Diffraction Standards, Swarthmore, PA.

[13] Ph. Colomban, J. P. Boilot, A. Kahn, G. Lucazeau, Nouv. J. Chim. 2 (1978) 21-32.

[14] Y. Furukawa, Y. Nakabayashi, S. Kawai, Solid State Ionics 7 (1982) 219-223.

[15] Y. Gotoh, K. Okada, N. Otsuka, Clay Sci. 7 (1988) 115-127.

[16] K. Kitajima, S. Taruta, N. Takusagawa, Clay Minerals 26 (1991) 435-440.

[17] H. Omi, K. Suzuki, S. Hayashi, Solid State Ionics 178 (2008) 1792-1797. 


\section{Figure legends}

Fig. 1. XRD patterns of (a) the synthesized Na-4-mica, and the ion-exchangers prepared by repeating ion exchange (b) one time, (c) three times and (d) six times. Na-4-mica, $\boldsymbol{\nabla}$ : mica peak, no mark: unknown)

Fig. 2. DTA and TG curves of the ion-exchanger prepared by repeating ion exchange four times.

Fig. 3. IR spectra of (a) the synthesized Na-4-mica, (b) the ion-exchanger prepared by repeating ion exchange four times and the heated ion-exchangers at (c) $600{ }^{\circ} \mathrm{C}$, (d) $700{ }^{\circ} \mathrm{C}$, (e) $800{ }^{\circ} \mathrm{C}$, (f) $900{ }^{\circ} \mathrm{C}$ and (g) $1000{ }^{\circ} \mathrm{C}$.

Fig. 4. XRD patterns of (a) the ion-exchanger prepared by repeating ion exchange four times and the heated ion-exchangers at (b) $700{ }^{\circ} \mathrm{C}$, (c) $800{ }^{\circ} \mathrm{C}$, (d) $900{ }^{\circ} \mathrm{C}$ and (e) $1000{ }^{\circ} \mathrm{C} .\left(\boldsymbol{\nabla}: \mathrm{NH}_{4}{ }^{+}\right.$ion-exchanger, $\bullet$ : other mica, no mark: unknown)

Fig. 5. Change in basal spacing $(c \cdot \sin \beta$ : $\bullet)$ and lattice constant $b(0)$ of the ion-exchanger by heating. Two values of $c \cdot \sin \beta$ were determined for the ion-exchanger heated at $800{ }^{\circ} \mathrm{C}$. Larger c. $\sin \beta$ originated in the ion-exchanger which retained $\mathrm{NH}_{4}{ }^{+}$ ions in the interlayer and smaller $\mathrm{c} \cdot \sin \beta$ originated in mica of which $\mathrm{NH}_{4}{ }^{+}$ions were decomposed into protons.

Fig. 6. Plots of $\log (\sigma \mathrm{T})$ against $1 / \mathrm{T}$ for the ion-exchangers heated at $(\diamond) 700^{\circ} \mathrm{C}$, $800^{\circ} \mathrm{C}$ and $(\Delta) 900^{\circ} \mathrm{C} .(\sigma:$ conductivity, T: temperature). 


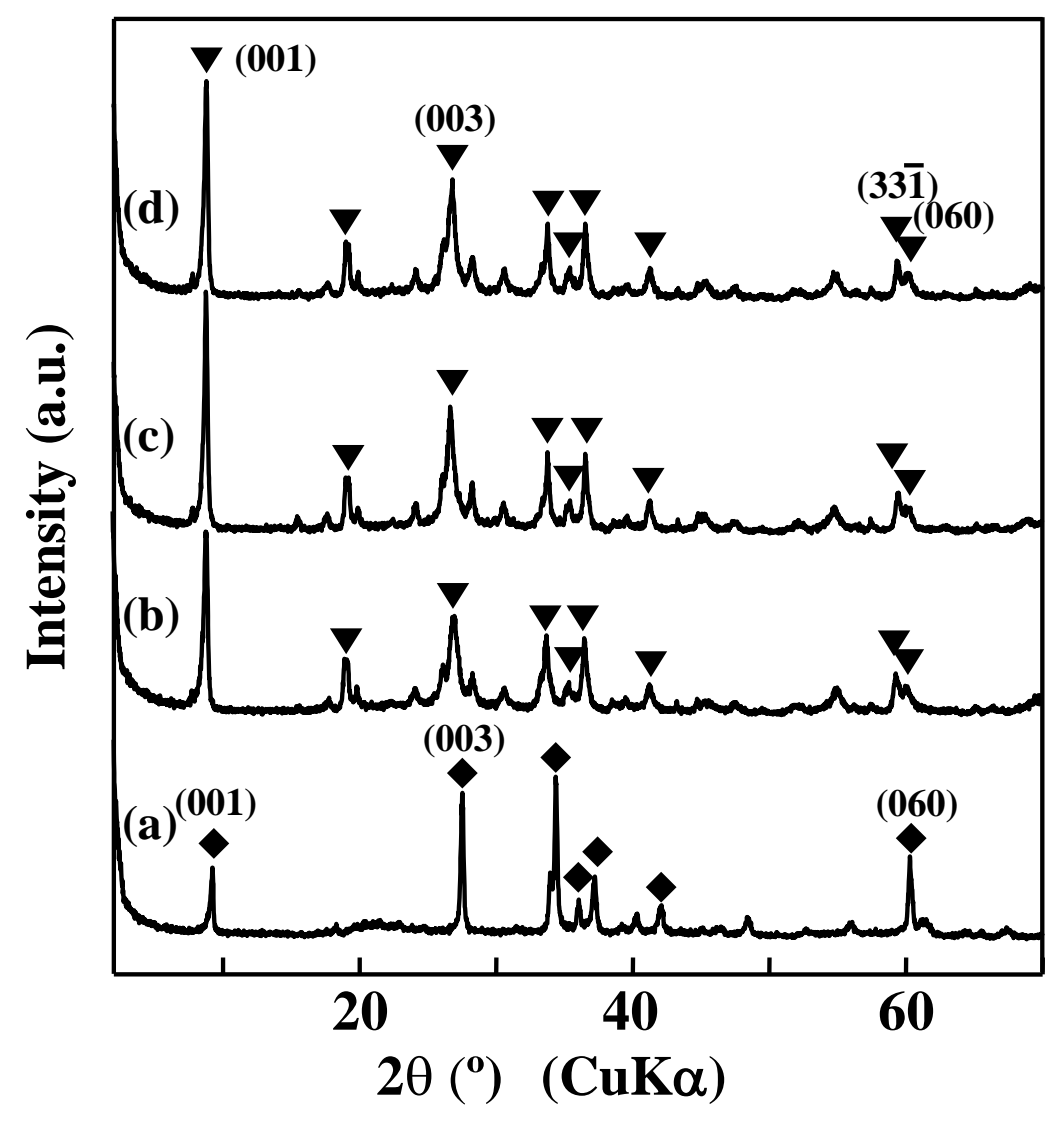

Fig. 1. XRD patterns of (a) the synthesized Na-4-mica, and the ion-exchangers prepared by repeating ion exchange (b) one time, (c) three times and (d) six times. $(\diamond$ : Na-4-mica, $\nabla$ : mica peak, no mark: unknown) 


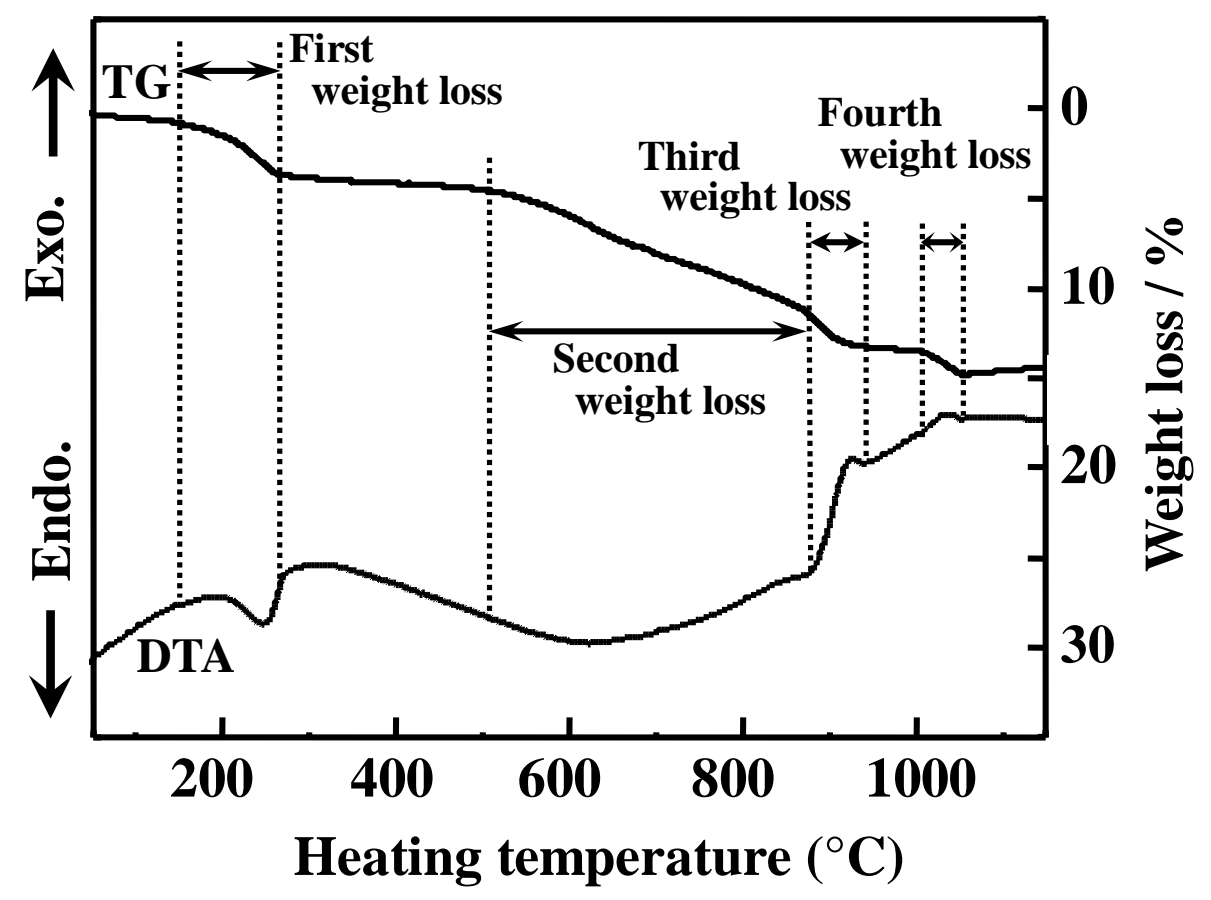

Fig. 2. DTA and TG curves of the ion-exchanger prepared by repeating ion exchange four times. 


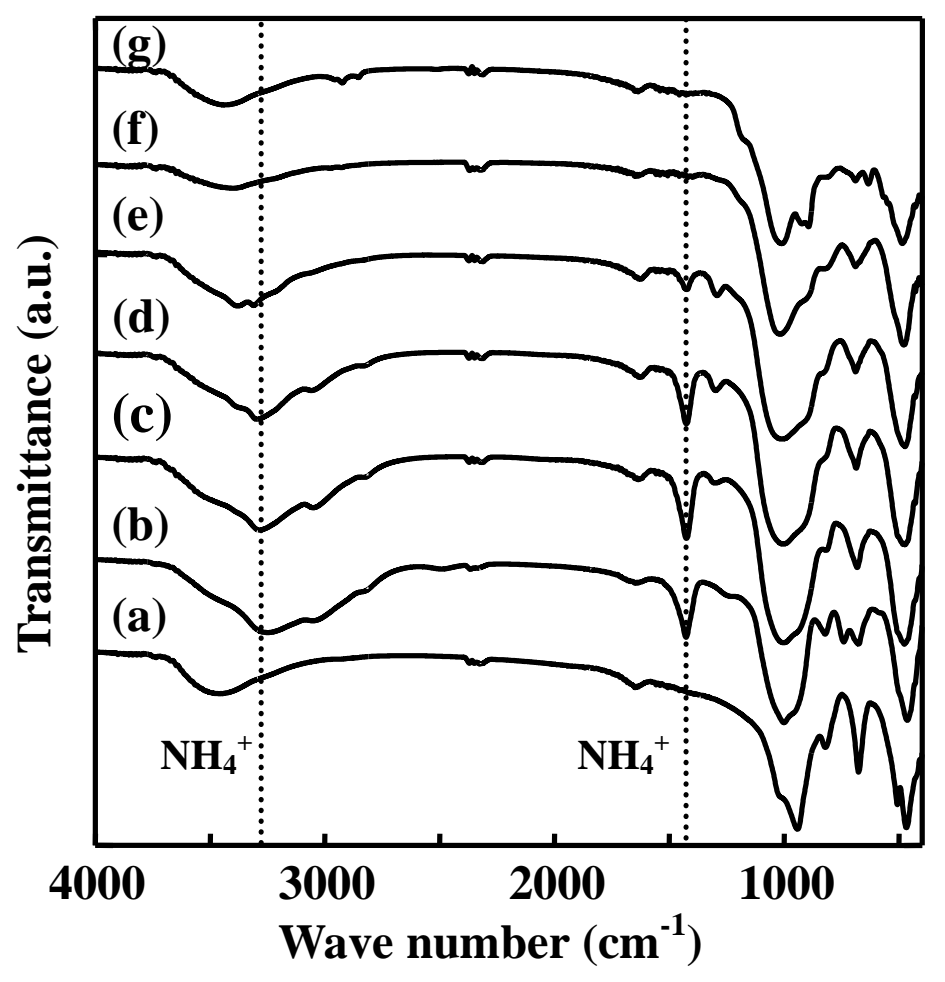

Fig. 3. IR spectra of (a) the synthesized Na-4-mica, (b) the ion-exchanger prepared by repeating ion exchange four times and the heated ion-exchangers at (c) $600{ }^{\circ} \mathrm{C}$, (d) $700{ }^{\circ} \mathrm{C}$, (e) $800{ }^{\circ} \mathrm{C}$, (f) $900{ }^{\circ} \mathrm{C}$ and (g) $1000{ }^{\circ} \mathrm{C}$. 


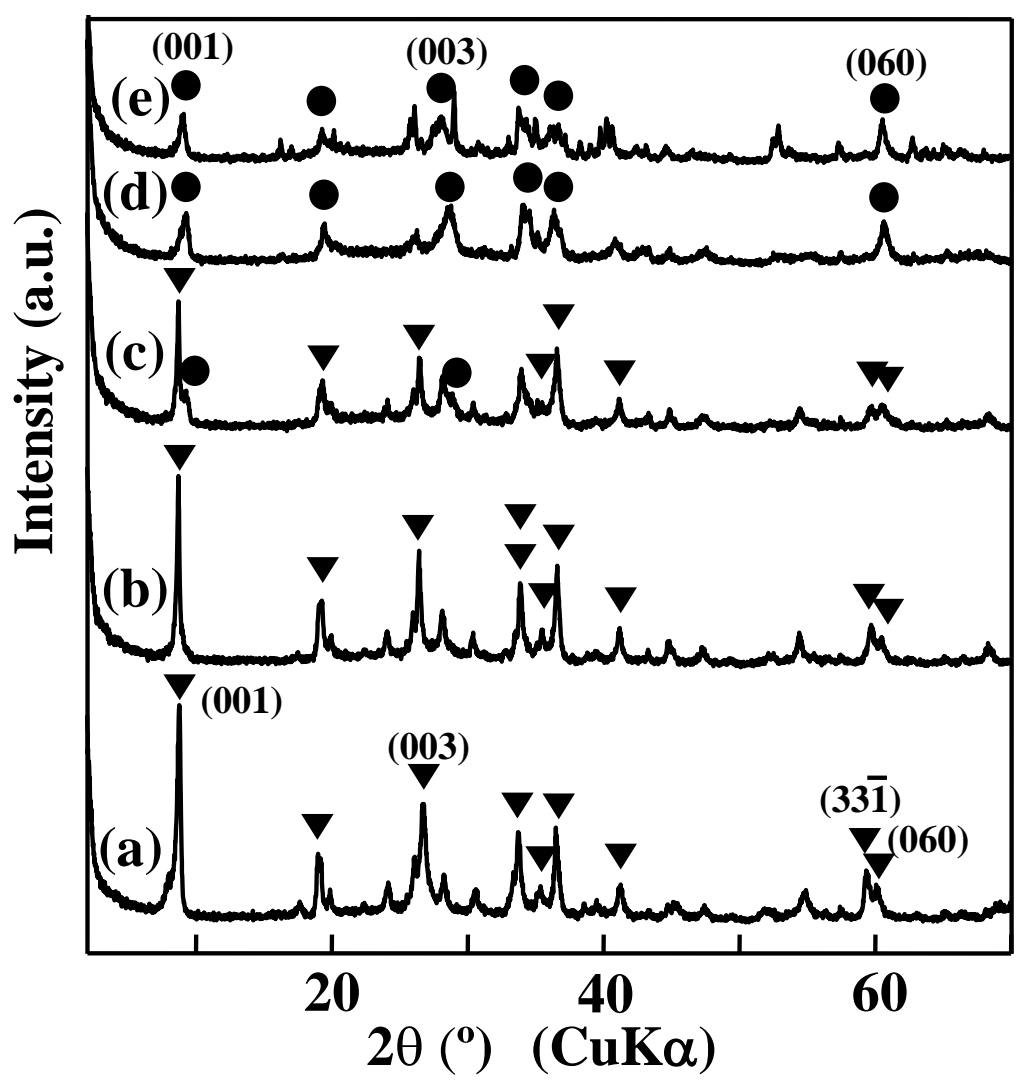

Fig. 4. XRD patterns of (a) the ion-exchanger prepared by repeating ion exchange four times and the heated ion-exchangers at (b) $700{ }^{\circ} \mathrm{C}$, (c) $800{ }^{\circ} \mathrm{C}$, (d) $900{ }^{\circ} \mathrm{C}$ and (e) $1000{ }^{\circ} \mathrm{C} . \quad\left(\boldsymbol{\nabla}: \mathrm{NH}_{4}{ }^{+}\right.$ion-exchanger, $\bullet$ : other mica, no mark: unknown) 


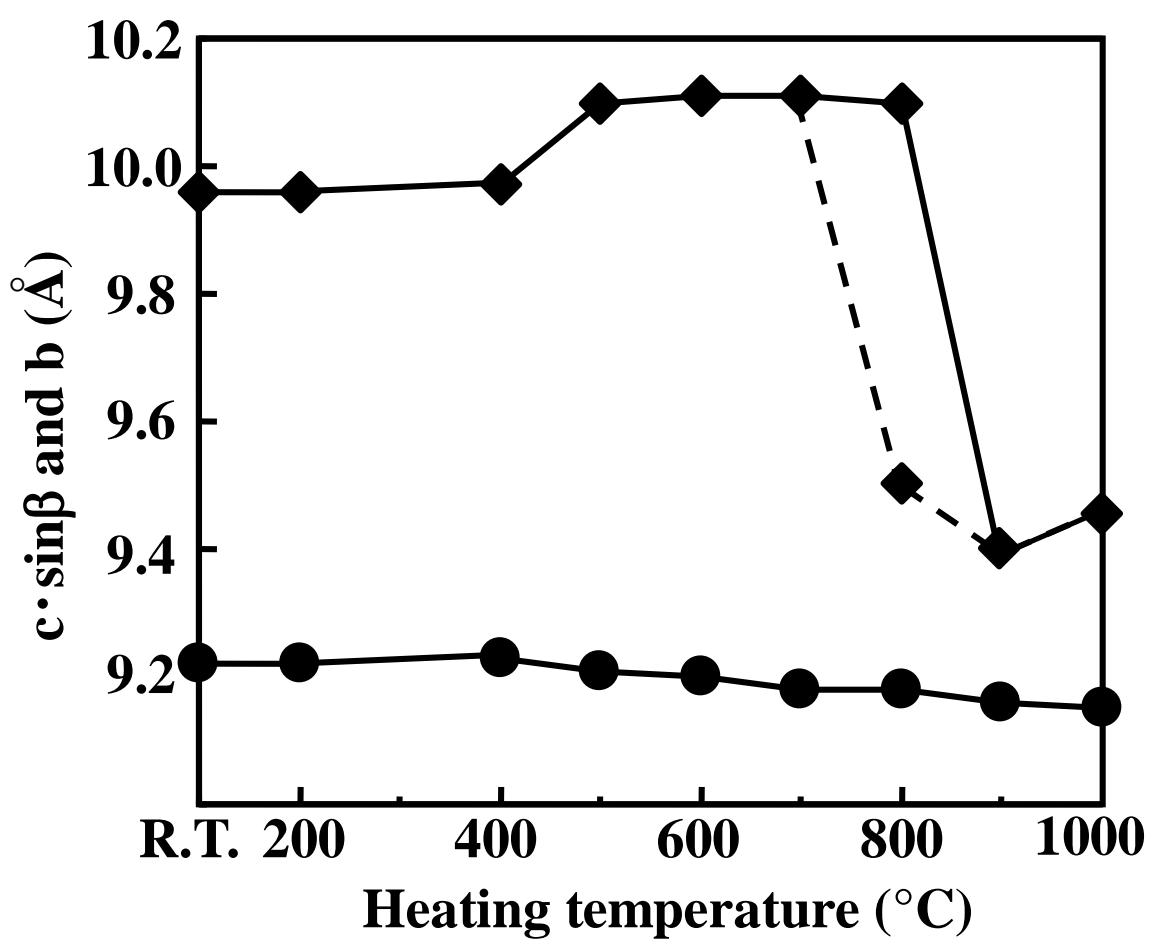

Fig. 5. Change in basal spacing $(c \cdot \sin \beta$ : $\bullet)$ and lattice constant $b(\boldsymbol{O})$ of the ion-exchanger by heating. Two values of $c \cdot \sin \beta$ were determined for the ion-exchanger heated at $800^{\circ} \mathrm{C}$. Larger $\mathrm{c} \cdot \sin \beta$ originated in the ion-exchanger which retained $\mathrm{NH}_{4}{ }^{+}$ions in the interlayer and smaller c. $\sin \beta$ originated in mica of which $\mathrm{NH}_{4}{ }^{+}$ions were decomposed into protons. 


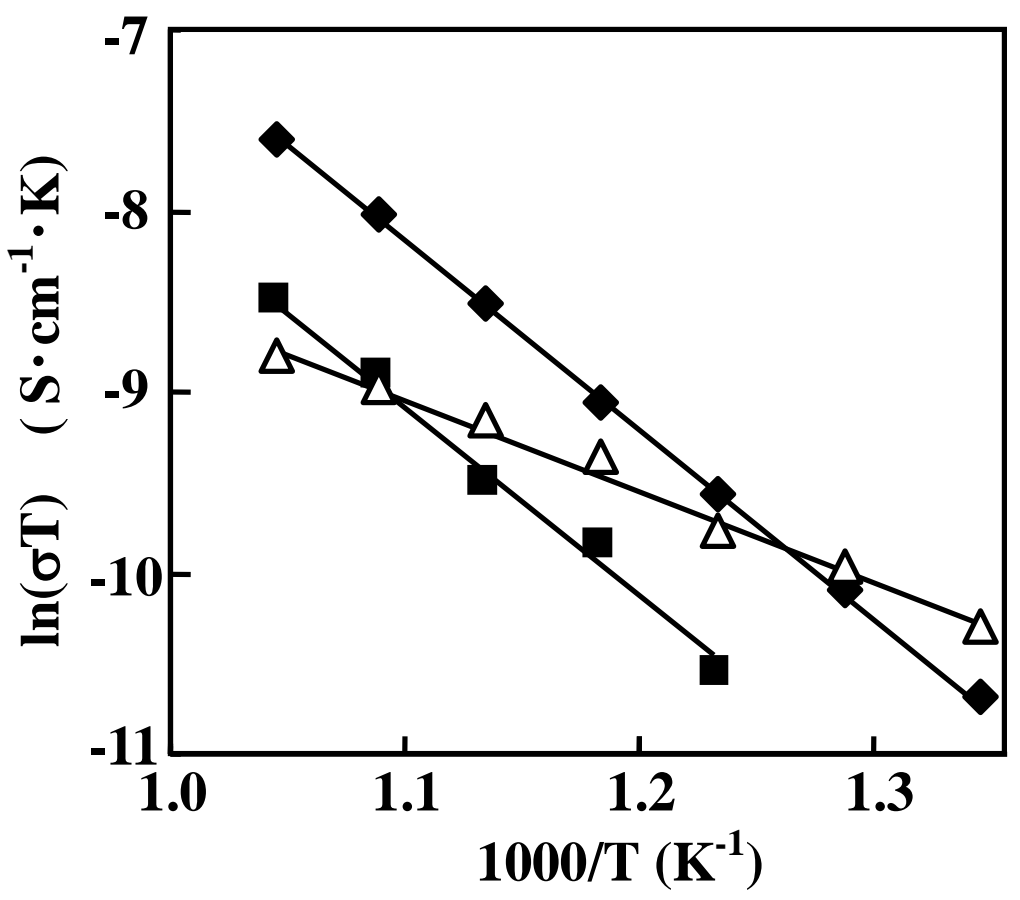

Fig. 6. Plots of $\log (\sigma \mathrm{T})$ against $1 / \mathrm{T}$ for the ion-exchangers heated at $(\diamond) 700^{\circ} \mathrm{C},(\square) 800^{\circ} \mathrm{C}$ and $(\Delta) 900^{\circ} \mathrm{C} .(\sigma$ : conductivity, $\mathrm{T}$ : temperature). 